\title{
Neutralidad liberal y libertad religiosa. Consecuencias de la STC 133/2010 para la práctica del home schooling*
}

\author{
Borja Barragué Calvo \\ Universidad Autónoma de Madrid
}

Recibido: 08.02.2011

Aceptado: 31.05 .2011

\begin{abstract}
Resumen: El trabajo analiza los principales argumentos a favor y en contra de la educación en casa, o home schooling. A partir de la distinción entre la autoridad de los padres y la de los poderes públicos en la educación de los menores, el artículo desarrolla sucesivamente uno y otro tema, haciendo especial énfasis en la argumentación desarrollada por la Sentencia núm. 133/2010 del Tribunal Constitucional que por el momento ha cerrado el debate en torno a esta práctica. El texto argumenta que la escolarización obligatoria, tal y como la regula la ley, no viola el principio de proporcionalidad en sentido estricto ni el de neutralidad del Estado liberal.
\end{abstract}

Palabras clave: home schooling, neutralidad estatal liberal, minimalismo educativo, comunitarismo, educación democrática.

Abstract: This work analyses the main arguments for and against the home schooling. Starting from the distinction between parental and state authority in education of children, the article successively develops both themes. Special emphasis is placed on the arguments put forward by the Judgment 133/2010 of the Spanish Constitutional Court that have settled the legal debate on the subject. The text argues that compulsory attendance laws neither violate the liberal principle of State neutrality nor the principle of proportionality in the strict sense.

Key words: home schooling, liberal state neutrality, minimalist education, communitarianism, democratic education.

Sumario: 1.- INTRODUCCIÓN; 2.- ASPECTOS PRINCIPALES DEL DERECHO A LA EDUCACIÓN EN ESPAÑA: 2.1.- La obligatoriedad de la enseñanza básica: los poderes públicos como garantes del derecho a la educación; 2.2.- El derecho del menor a una educación orientada al desarrollo pleno de su personalidad; 2.3.- El derecho de los padres a elegir para sus hijos una educación de acuerdo con sus convicciones; 3.- LÍMITES A LA AUTORIDAD DE LOS PADRES EN LA EDUCACIÓN DE SUS HIJOS: EL CASO DEL HOME SCHOOLING: 3.1.- Actualidad y razones del home schooling; 3.2.- El reconocimiento de la educación en casa en la práctica jurisprudencial estadounidense; 3.3. La Sentencia 133/2010 del Tribunal Constitucional español; 4.- LÍMTES A LA AUTORIDAD

* Este trabajo ha sido realizado en el marco del Proyecto de Investigación DER200908138, financiado por el Ministerio de Ciencia e Innovación. 


\section{DEL ESTADO: ESCOLARIZACIÓN OBLIGATORIA Y EL PRINCIPIO} LIBERAL DE NEUTRALIDAD: 4.1. Algunas precisiones previas sobre la tesis liberal de la neutralidad del Estado; 4.2. La crítica a la escolarización obligatoria de los teóricos del libre mercado: el minimalismo educativo; 4.3. La crítica comunitarista: autonomía de la familia y objeción de conciencia; 4.4. La objeción del liberalismo pluralista: autonomía del menor, diversidad y tolerancia.

\section{INTRODUCCIÓN}

El derecho a la educación es un tema de discusión recurrente en la filosofía del derecho, pues en las sociedades actuales existe cierto consenso acerca de que, primero, no es posible formar una sociedad democrática y estable sin una amplia aceptación de un conjunto compartido de valores y un grado mínimo de alfabetización de la mayoría de la ciudadanía; y, segundo, que la educación contribuye a ambos objetivos ${ }^{1}$.

Sin embargo, cuando los juristas teóricos debaten acerca de los límites entre las autoridades estatal y parental sobre la educación de los jóvenes, a menudo lo hacen únicamente desde el análisis de las sentencias de los tribunales al respecto. En el terreno de la filosofía del derecho anglosajona, la atención se ha centrado en dos casos resueltos por tribunales estadounidenses: la sentencia del Tribunal Supremo (TS) recaída con motivo del caso Wisconsin v. Yoder, de 1972, y la del Tribunal del Sexto Circuito en la decisión de Mozert v. Hawkins County Board of Education ${ }^{2}$, de 1987. En el ámbito español, cabe destacar igualmente dos casos: el primero, el de veintitrés familias pertenecientes a un movimiento religioso denominado "Niños de Dios", y que concluyó con las sentencias núm. 1669/1994, de 30 de octubre, del TS, y 260/1994, de 11 de noviembre, del Tribunal Constitucional (TC); el segundo, en el que dos familias de Málaga habían asumido la educación en el hogar de sus hijos de 6, 10 y 13 años, resuelto recientemente por la Sentencia del TC 133/2010, de 2 de diciembre (STC 133/2010). Aunque comprensible, por cuanto contribuyen a ilustrar un buen número de tensiones centrales a la teo-

\footnotetext{
${ }^{1}$ En tal sentido, el primer párrafo del Preámbulo de la Ley Orgánica 6/2006, de 3 de mayo, de Educación (LOE), afirma que la "educación es el medio más adecuado para construir su personalidad [de los jóvenes], desarrollar al máximo sus capacidades, conformar su propia identidad personal y configurar su comprensión de la realidad, integrando la dimensión cognoscitiva, la afectiva y la axiológica. Para la sociedad, la educación es el medio de transmitir y, al mismo tiempo, de renovar la cultura y el acervo de conocimientos y valores que la sustentan, de extraer las máximas posibilidades de sus fuentes de riqueza, de fomentar la convivencia democrática y el respeto a las diferencias individuales, de promover la solidaridad y evitar la discriminación, con el objetivo fundamental de lograr la necesaria cohesión social."

${ }^{2}$ Existe una literatura abundante sobre el tema. Ciñéndome a la teórica jurídica, y sin ánimo exhaustivo, pueden verse; CALLAN, 1997; KYMLICKA, 1995; BROOKS, 1990; GUTMANN, 1995; GORDON, 1996; GALSTON, 1995; MACEDO, 2000; ARNESON y SHAPIRO, 1996; McVICKER, 1985; o TOMPKINS, 1991.
} 
ría política liberal en general, la extraordinaria atención que han despertado estos casos ha podido eclipsar un fenómeno educativo que de forma creciente plantea el problema de fijar los límites a la autoridad parental en la educación de los menores, y que, en comparación con los padres Amish que rehúsan enviar a sus hijos al colegio o los ultracatólicos que objetan a determinadas materias curriculares, comienza a ser mucho más frecuente: el home schooling.

En definitiva, las dos grandes cuestiones que desde una óptica filosófico jurídica plantea el home schooling son; por un lado, si el derecho a la educación radica en la total libertad de los padres para orientar a los hijos hacia las convicciones morales, religiosas o filosóficas que crean más adecuadas a su formación intelectual, o, en cambio, consiste esencialmente en la escolarización del menor, incluso de forma obligatoria, si ello fuese necesario; y por otro lado, hasta qué punto el principio de neutralidad estatal autoriza constitucionalmente la imposición de la escolarización. En la medida en que la cuestión de la vulneración del principio de neutralidad sólo se puede plantear bajo el presupuesto de que se reconozca la validez del deber legal de escolarizar en centros oficiales, comenzaré analizando -desde una doble óptica legislativa y jurisprudencial- esta cuestión dejando para el final, a modo de conclusión, la discusión sobre aquélla. Así pues, empezaré exponiendo, en el apartado segundo, la regulación constitucional de los aspectos implicados en el derecho a la educación, para ver a continuación su formulación en los textos internacionales que los recogen y su desarrollo en la legislación ordinaria. Ya en el apartado tercero, analizaré la ponderación que de estos elementos han realizado los tribunales estadounidenses y el TC español.

\section{ASPECTOS PRINCIPALES DEL DERECHO A LA EDUCACIÓN EN ESPAÑA}

\subsection{La obligatoriedad de la enseñanza básica: los poderes públicos como garantes de la educación}

La generalización de la educación elemental ha sido tardía en España. La enseñanza básica y obligatoria data de la Ley Moyano de 1857, cuyo artículo 7 establecía que la "primera enseñanza elemental es obligatoria para todos los españoles. Los padres o tutores o encargados enviarán a las escuelas públicas a sus hijos y pupilos desde la edad de seis años hasta la de nueve"3.

${ }^{3}$ La Ley de Instrucción Pública, de 9 de septiembre de 1857, puede consultarse en la dirección de Internet: http://personal.us.es/alporu/historia/ley_moyaNo_texto.htm. Aunque sin prurito exhaustivo ni historicista, conviene aclarar que en España la primera regulación del derecho-deber a la educación se encuentra en la Constitución de 1812 (Título IX: De la instrucción pública). Posteriormente, hasta llegar a la Ley Moyano de 1857, en 1814, en el Proyecto de Decreto sobre el arreglo general de la Enseñanza Pública; en 1824, en el Plan literario de estudios y arreglo general de las Universidades del Reino; en 1836, en el Plan de Instrucción Pública y, en fin, en 1845, en el denominado Plan Pidal. 
Además, el art. 8 de la ley incorporaba una amenaza de sanción a los padres o tutores que incumplieran su deber legal, pues de no escolarizarlos "habiendo escuela en el pueblo o a distancia tal que puedan los niños concurrir a ella cómodamente, serán amonestados y compelidos por la Autoridad y castigados en su caso con la multa de 2 hasta 20 reales".

Pero por lo que se refiere a su regulación constitucional actual, los números 4 y 5 de la Constitución Española (CE) establecen lo siguiente:

"4. La enseñanza básica es obligatoria y gratuita.

5. Los poderes públicos garantizan el derecho de todos a la educación, mediante una programación general de la enseñanza, con participación efectiva de todos los sectores afectados y la creación de centros docentes".

El derecho a la educación, como todos los que conforman el catálogo de los derechos humanos, implica una exigencia moral especialmente fuerte, en la medida en que cuando esas pretensiones básicas quedan justificadas, "fundamentan obligaciones morales correlativas [...] que deben ser garantizadas a través de instituciones operativas, como pueden serlo algunos sistemas estatales"4. La educación constituye una exigencia moral de tanta importancia que su satisfacción no se deja a la autonomía de la voluntad, sino que se acompaña de deberes que afectan a los tres agentes implicados en la relación docente: padres, menores e instituciones educativas ${ }^{5}$.

En cuanto al Derecho Internacional, y puesto que de acuerdo con el art. 96.1 CE los "tratados internacionales válidamente celebrados, una vez publicados oficialmente en España, formarán parte del ordenamiento", el artículo 26.1 de la Declaración de Derechos Humanos de 1948 (DUDH), dispone que la "instrucción elemental será obligatoria", la "técnica y profesional habrá de ser generalizada" y "el acceso a los estudios superiores será igual para todos". En el mismo sentido se expresan los arts. 4.a) de la Convención contra las Discriminaciones en la Enseñanza de Naciones Unidas de 1960; 13.2.a) del Pacto Internacional de Derechos Económicos, Sociales y Culturales de 1966 (PIDESC); 28.1 de la Convención de las Naciones Unidas sobre los Derechos del Niño de 1989 (CDN); y 14 de la Carta de los Derechos Fundamentales de la Unión Europea 2000 (CDFUE).

Con respecto a su desarrollo en la legislación educativa española, hubo que esperar hasta mediados de la década de los ochenta para que la Ley Orgánica 8/1985, de 3 de julio, reguladora del Derecho a la Educación (LODE) ${ }^{6}$,

${ }^{4}$ RUIZ MIGUEL, 1994: 654-55.

${ }^{5}$ Cf. REDONDO, 2003: 72.

${ }^{6}$ BOE número 159 , de 4 de julio de 1985 . A pesar de que aquí me voy a ceñir a la regulación de la educación en las leyes educativas posteriores a la CE, conviene aclarar, como hace la LODE en su Preámbulo, que ya la "Ley General de Educación de 1970 estableció la obligatoriedad y gratuidad de una educación básica unificada. Concebía ésta como servicio público, y responsabilizaba prioritariamente al Estado de su provisión." 
hiciera realidad la prescripción constitucional de la obligatoriedad, al disponer su artículo primero que:

"Todos los españoles tienen derecho a una educación básica que les permita el desarrollo de su propia personalidad y la realización de una actividad útil a la sociedad. Esta educación será obligatoria y gratuita en el nivel de Educación General Básica y, en su caso, en la formación profesional de primer grado, así como en los demás niveles que la Ley establezca."

Posteriormente, tanto la Ley Orgánica 1/1990, de 3 de octubre, de Ordenación General del Sistema Educativo (LOGSE) ${ }^{7}$, en su art. 5.2, como la Ley Orgánica 10/2002, de 23 de diciembre, de Calidad de la Educación (LOCE [art. 9.1, in fine] $)^{8}$ y la vigente Ley Orgánica 2/2006, de 3 de mayo, de Educación (LOE [art. 4.1]) ${ }^{9}$, regulan la educación básica de acuerdo con lo dispuesto en la Constitución; es decir, configurándola con un carácter obligatorio y gratuito para todos los menores.

La configuración de la enseñanza como un derecho de toda persona que deben prestar los poderes públicos de forma gratuita implica asumir la exigencia de hacer efectivo el derecho de todos a la educación. Ello requiere la adopción de medidas que pueden articularse de formas muy diversas, planteándose así la cuestión del papel del Estado en la educación. Aquí es posible encontrar dos posturas diferentes. Por un lado, quienes piensan que es legítimo que los poderes públicos se hagan cargo de la financiación y administración del sistema educativo; por el otro, los que creen que el Estado debería limitarse a su financiación, instrumentada mediante el pago a los padres de un cheque por los gastos educativos de sus hijos, dejando la administración a la iniciativa privada. En cualquier caso, el encargo a los poderes públicos de garantizar la efectividad del derecho a la educación exige la regulación de las competencias en materia educativa de los distintos ámbitos de la Administración Pública ${ }^{10}$.

\subsection{El derecho del menor a una educación orientada al desarrollo pleno de su personalidad}

De acuerdo con en el art. 27.2 CE, la "educación tendrá por objeto el pleno desarrollo de la personalidad humana en el respeto a los principio democráticos de convivencia y a los derechos y libertades fundamentales." Además, y dado que el derecho del menor a la educación es un derecho

${ }^{7}$ BOE número 238, de 4 de octubre de 1990.

${ }^{8}$ BOE número 307, de 24 de diciembre de 2002.

${ }^{9}$ BOE número 106, de 4 de mayo de 2006.

${ }^{10}$ Vid., Ley 7/1985, de abril, Reguladora de las Bases del Régimen Local; Real Decreto 2274/1993, de 22 de diciembre, de Cooperación de las Corporaciones Locales con el Ministerio de Educación y Ciencia, y los decretos de las consejerías que regulan los sistemas educativos en cada Comunidad Autónoma. 
fundamental, éste debe interpretarse "de conformidad con la Declaración Universal de Derechos Humanos y los tratados y acuerdos internacionales sobre las mismas materias ratificados por España" (art. 10.2 CE).

En el ámbito, pues, del Derecho Internacional de los Derechos Humanos, el art. 26.2 de la DUDH de 1948 señala que la "educación tendrá por objeto el pleno desarrollo de la personalidad humana y el fortalecimiento del respeto a los derechos humanos y a las libertades fundamentales". Un sentido en el que se pronuncian también el primer inciso del art.29.1 de la CDN y el art. 13.1 PIDESC.

En cuanto a su desarrollo normativo en la legislación ordinaria, el derecho de los menores a una educación cuyo fin sea el pleno desarrollo de su personalidad en el respeto a los principios democráticos ha sido ampliamente reconocido por las sucesivas leyes que desde la aprobación de la Constitución han regulado el período de enseñanza básica obligatoria ${ }^{11}$. De acuerdo con el vigente art. 2.1. LOE, el sistema educativo español se orientará a la consecución del "pleno desarrollo de la capacidad de los alumnos" (apartado a), así como una "educación en el respeto de los derechos y libertades fundamentales" (apartado b).

\subsection{El derecho de los padres a elegir para sus hijos una educación acorde a sus convicciones}

La CE reconoce el derecho de los padres a elegir la educación de sus hijos conforme a sus convicciones en el art. 27.3:

"Los poderes públicos garantizan el derecho que asiste a los padres para que sus hijos reciban la formación religiosa y moral que esté de acuerdo con sus propias convicciones."

Ahora bien, de acuerdo con la STS núm. 2609, de 30 de junio de 1994, el art. 27.3 CE es un "derecho de protección indirecta" cuya materialización se

${ }^{11}$ Así, en primer lugar, el artículo segundo de la LODE establece en sus dos primeros números que la "actividad educativa, orientada por los principios y declaraciones de la Constitución, tendrá [...] los siguientes fines: a) El pleno desarrollo de la personalidad del alumno; b) La formación en respeto de los derechos y libertades fundamentales y en el ejercicio de la tolerancia y de la libertad dentro de los principios democráticos de convivencia." En segundo término, la LOGSE, tras afirmar en su Preámbulo que el "objetivo primero y fundamental de la educación es el de proporcionar [...] una formación plena que les permita conformar su propia y esencial identidad", y que en "la educación se transmiten y ejercitan los valores que hacen posible la vida en sociedad, singularmente el respeto a todos los derechos y libertades fundamentales, se adquieren los hábitos de convivencia democrática y de respeto mutuo, se prepara la participación responsable en las distintas actividades e instancias sociales", señala en su art. 1 que el "sistema educativo español [...] se orientará" al "pleno desarrollo de la personalidad del alumno" así como a la "formación en el respeto de los derechos y libertades fundamentales [...]". Más tarde la LOCE (art. 1, letra a.), insiste en esta misma cuando dice que la equidad es un principio rector del sistema educativo, ya que "garantiza una igualdad de oportunidades de calidad, para el pleno desarrollo de la personalidad a través de la educación $[\ldots] "$. 
produce a través de otros como la libertad de enseñanza, la creación de centros docentes o la neutralidad ideológica de los centros públicos. El derecho del art. 27.3 lo es así derivado del derecho del menor a la educación, en cuyo proceso los padres podrán influir tanto dentro como fuera de la escuela -dentro porque los poderes públicos son destinatarios del deber de tener en cuenta las convicciones religiosas particulares, y fuera en tanto que los padres son libres para educar a los menores después del horario escolar y durante los fines de semana o días de vacación ${ }^{12}$-, además de mediante la creación de centros docentes que, dentro del marco de la programación general de la enseñanza diseñado por los poderes públicos, se adecuen a sus convicciones morales, religiosas o filosóficas. Como escribe el Magistrado Vicente Gimeno Sendra en su voto particular a la STC 260/1994 en el caso de los "Niños de Dios",

"Es cierto que la Constitución confiere a los padres el derecho, no sólo a impartir en el seno de la familia (o unión de hecho) la religión que estimen conveniente, sino también el de poder enviar a sus hijos al Colegio religioso que deseen e incluso el no menor derecho fundamental a exigir de los poderes públicos la formación religiosa que se adecue a sus convicciones [...]; pero, en mi opinión, la libertad religiosa no ampara un supuesto derecho de los padres a la no escolarización de los hijos bajo el pretexto de que sólo ellos han de impartir la educación que estimen conveniente."

La anterior conclusión ha sido recientemente avalada por la interpretación del art. 27 CE realizada por la STC 133/2010 en relación con los textos y acuerdos internacionales sobre derechos humanos ratificados por España. Por un lado, en cuanto a la interpretación del art. 27.3 de acuerdo con la DUDH, el TC observa con acierto que el art. 26.3 reconoce genéricamente a los padres el "derecho preferente a escoger el tipo de educación que habrá de darse a sus hijos" (FJ 6). Ahora bien, a los efectos que aquí nos interesan, de delimitación de la autoridad de los padres en la educación de los menores en el supuesto específico de que aquellos objeten a la escolarización obligatoria, es decir, en los casos de padres home schoolers, esta expresión no puede entenderse "como un derecho general del cual el derecho reconocido en nuestro art. 27.3 CE operaría como especie, sino como una formulación genérica de este último que, por lo demás, ha de interpretarse sistemáticamente en relación con el art. 26.1 DUDH" (ibíd.), que dispone que la "instrucción elemental será obligatoria". La misma solución que se alcanza en la Sentencia cuando el art. $27 \mathrm{CE}$ es interpretado en relación con otros instrumentales internacionales como el Pacto Internacional de Derechos Civiles y Políticos (PIDCP), cuyo art. 18.4 afirma que "la libertad de los padres y, en su caso, de los tutores legales, para garantizar que los hijos reciban la educación religiosa y moral que esté de acuerdo con sus propias convicciones", o el PIDESC, cuyo art. 13.3 reconoce el derecho de los padres o tutores a "escoger para sus

${ }^{12}$ Cf. STC 133/2010, FJ 8. 
hijos o pupilos escuelas distintas de las creadas por las autoridades públicas [...] y hacer que sus hijos o pupilos reciban la educación religiosa o moral que esté de acuerdo con sus propias convicciones."

En cuanto a la interpretación del art. $27 \mathrm{CE}$ de acuerdo con el Derecho de la Unión Europea, el TC (FJ 6) señala que a pesar de que en su art. 14 la CDFUE reconoce el "derecho de los padres a garantizar la educación y la enseñanza de sus hijos conforme a sus convicciones religiosas, filosóficas y pedagógicas", esta última precisión debe entenderse referida a aquellas opciones pedagógicas que resulten de convicciones de tipo religioso o filosófico, pues el art. 14 CDFUE se inspira tanto en las tradiciones constitucionales comunes a los Estados miembros como en el art. 2 del Protocolo adicional al Convenio Europeo para la Protección de los Derechos Fundamentales y las Libertades Públicas (CEDH). El Tribunal Europeo de Derechos Humanos (TEDH) ha reconocido en tal sentido que la escolarización obligatoria en el ámbito de la educación primaria no priva a los padres de su derecho a ejercer sobre sus hijos las funciones de educadores propias de su condición parental, ni a guiar a sus hijos hacia un camino que resulte conforme con sus propias convicciones religiosas o filosóficas: lo que no pueden hacer estas convicciones es amparar cualquier tipo de consideración relativa a la educación, con independencia de cuál sea su naturaleza ${ }^{13}$.

Finalmente, el ulterior desarrollo normativo en la legislación española del derecho de los padres a que sus hijos reciban una formación religiosa y moral que esté de acuerdo con las propias convicciones resulta, al compararse con el del menor a una educación orientada al pleno desarrollo de su personalidad, menos claro ${ }^{14}$. Sólo el art. 4.1 LODE reconoce, en su redacción actual tras haber sido reformado por la Disposición final primera de la LOE, que los padres o tutores, en relación con la educación de sus hijos o pupilos, tienen el derecho "a escoger centro docente tanto público como distinto de los creados por los poderes públicos" para sus hijos (inciso segundo), así como a que éstos reciban "la formación religiosa y moral que esté de acuerdo con sus propias convicciones" (inciso tercero).

\section{LÍMITES A LA AUTORIDAD DE LOS PADRES EN LA EDUCA- CIÓN DE SUS HIJOS: EL CASO DEL HOME SCHOOLING}

\subsection{Actualidad y razones del home schooling}

La escuela es una institución reciente en la historia de la humanidad. Tradicionalmente y con independencia de la cultura que consideremos, los niños han sido educados en casa por sus padres o, sólo en los casos de familias aco-

\footnotetext{
${ }^{13}$ Cf., entre otros, Caso Kjeldsen y otros v. Dinamarca, Sentencia del TEDH de 7 de diciembre de 1975. Citado en la STC 133/2010, FJ 6.

${ }^{14}$ Desde el Derecho Eclesiástico, de acuerdo, cf. MANTECÓN SANCHO, 2006: 2; RUANO ESPINA, 2009: 13.
} 
modadas, por tutores (o preceptores). De modo que a finales del siglo XVIII y principios del XIX el "unschooling" era la práctica habitual en las sociedades occidentales. Sin embargo, a partir de la promulgación de las primeras leyes que instituyeron conjuntamente la obligatoriedad de la enseñanza básica y la escuela pública a mediados del s. XIX, la educación en casa se convirtió en un fenómeno aislado.

Actualmente, sin embargo, el home schooling no constituye una práctica tan marginal. Esta afirmación se apoya en dos tipos de consideraciones. Primero están los datos. Aunque para la mayoría de países no existen estadísticas oficiales, porque los gobiernos no elaboran informes al respecto, según las estimaciones más fiables aproximadamente un millón y medio de niños estadounidenses y alrededor de 1.500 familias españolas educan a sus hijos en casa ${ }^{15}$. Por el otro lado están los factores que habrían contribuido a que el fenómeno se extienda y que por consiguiente explican, al menos parcialmente, los datos anteriores. Aquí hay que distinguir dos circunstancias.

En primer término está el factor tecnológico. Gracias a Internet, los home schoolers han constituido redes de trabajo virtuales en las que intercambian recursos didácticos, jurídicos, etc. Pero en segundo lugar, y en lo que aquí más nos importa, está el elemento jurídico. En España, la sentencia del TC en el caso "Niños de Dios", al negar la violación del derecho a la educación en un supuesto en que estaba acreditada la falta de escolarización de los niños y denegar consiguientemente el amparo a la Generalitat, dejó sin resolver el problema de quién puede asumir la autoridad de la educación en último término y con qué extensión. En esa coyuntura de relativa incertidumbre, la Ley 12/2009, de 10 de julio, de Educación de Cataluña, reconoció una modalidad de enseñanza en régimen no presencial en su art. 55. No obstante, según lo establecido en su Preámbulo, tales enseñanzas están "dirigidas a los alumnos de edad superior a la de escolarización obligatoria", aunque "excepcionalmente" se admite también la impartición en dicha modalidad de las "enseñanzas obli-

\footnotetext{
${ }^{15}$ Véase, para EEUU, Centro Nacional de Estadísticas sobre Educación, "1.5 Million Home schooled Students in the United States in 2007"; para España, Público, "1.500 familias educan a sus hijos en casa", 22 de agosto de 2010, y El Mundo (Magazine), "Crecer bien sin ir al colegio", 14 de enero de 2007, que estima que unos 4.000 niños españoles no van a la escuela. En términos porcentuales, representan el $2.9 \%$ de los menores estadounidenses en edad escolar y el $0,05 \%$ de los españoles. Este último dato se obtiene de multiplicar por cien el resultado de la división de la estimación de población infantil home schooler (3.500), entre los alumnos escolarizados en las Etapas Infantil (1.873.153), Primaria (2.749.496) y Secundaria Obligatoria (1.786.106) en España el curso 2010-2011. (Vid., Ministerio de Educación, "Datos y Cifras. Curso escolar 2010/2011". Disponible online en la dirección de Internet: http://educacion.es/dctm/ministerio/horizontales/prensa/documentos/2010/septiembre/datosy-cifras-2010-2011.indd.pdf?documentId=0901e72b803eceed).

Estos datos, cuyo interés para un análisis ius-filosófico es relativo, se exponen a los meros efectos de contextualizar la discusión.
} 
gatorias y las demás enseñanzas que, en determinadas circunstancias, establezca el Departamento" (art. 55.2, in fine) ${ }^{16}$.

En EEUU, la sentencia del caso Yoder animó a los defensores del home schooling a presentar sus reivindicaciones ante los poderes judicial y legislativo de los estados, con un notable éxito: la educación en casa es legal en todos los estados, en la mayoría está más (por ejemplo, Massachusetts) o menos (California) regulada, y en muchos tiene un estatuto propio ${ }^{17}$. Pero los defensores del home schooling han llevado sus reclamaciones más allá del ámbito estatal.

En una de sus secciones ("Room for Debate"), The New York Times se preguntaba recientemente si los home schoolers merecen una desgravación fiscal $^{18}$. La nueva mayoría republicana en la Cámara de Representantes ha decidido cuestionar la autoridad del gobierno federal en el sistema público de educación, así como limitar el poder de los estados en otras áreas. Una de sus prioridades es la elaboración de una nueva ley federal que reconozca a los padres el derecho a una desgravación fiscal si sus hijos son educados en casa, pues actualmente sólo Illinois, Louisiana y Minnesota conceden algún tipo de ayuda a los padres home schoolers.

Por lo demás, las razones que aducen los padres para el home schooling son muy diversas: pedagógico-académicas, socio-laborales, la convicción de que las necesidades educativas especiales de los niños discapacitados van a ser mejor atendidas en casa, o el miedo a la violencia en la escuela. Pero mientras que los casos de home schooling en la década de los setenta "respondían a motivaciones humanistas, liberales y pedagógicas", la mayor parte de los casos ac-

${ }^{16}$ El sentido del pronunciamiento de la STC 133/2010 hace aconsejable revisar la constitucionalidad de este último inciso.

${ }^{17}$ Esta expansión regulatoria se debe fundamentalmente a la presión política y social ejercida por los defensores del home schooling, pues aunque la sentencia del caso Yoder "nunca ha sido invalidada, tampoco ha servido de precedente para una expansión general de la autoridad parental a expensas de la potestad de los poderes públicos para regular la educación de los menores. Los tribunales, incluyendo el Tribunal Supremo, han tendido a limitar la sentencia Yoder a sus circunstancias idiosincráticas, evitando las oportunidades de afianzarla o de ampliar su alcance" (ARNESON y SHAPIRO, 1996: 366-367). En efecto, desde el caso Pierce v. Society of Sisters, 268 U.S. 510 a 534 (1925), una larga serie de sentencias judiciales viene apoyando la idea de que a los padres no les asiste un derecho general a decidir sobre la educación de los menores, al margen de las leyes educativas de los Estados: cf., Prince v. Massachusetts, 321 U.S. 158 a 168 (1944); Employment Division v. Smith, 494 U.S. 872 (1989); o Minnesota v. Hershberger 495 U.S. 901 (1990).

Creo que en este mismo sentido puede entenderse también la críptica afirmación con que Burger concluye la opinión del tribunal en Yoder, cuando dice que "nada que mantengamos pretende socavar la aplicabilidad general de las leyes estatales relativas a la escolarización obligatoria."

${ }^{18}$ The New York Times, 4 de enero de 2011. Información disponible online en la dirección de Internet: http://www.nytimes.com/roomfordebate/2011/01/04/do-home-schoolers-deservea-tax-break (Consultado por última vez el 13/01/2011). 
tuales "son expresión de convicciones ideológicas conservadoras y religiosas"19. Como los padres de los casos Yoder y Mozert y las 23 familias pertenecientes a la organización "Niños de Dios", hoy parece que la razón que la mayoría, aunque no todos, de los padres alegan para educar en casa es que la escuela es incapaz de satisfacer las necesidades espirituales o religiosas de los menores.

\subsection{El reconocimiento de la educación en casa en la práctica jurispru- dencial estadounidense}

De entre los países donde está reconocido legalmente, EEUU probablemente sea el país más tolerante con el fenómeno del home schooling. Pero como la obligatoriedad de la enseñanza básica cuando se observa desde un prisma histórico, este reconocimiento es también muy reciente. Como dice Steven D. Reschly en su comentario a la sentencia Yoder, "el primer conflicto ocurrió en el condado de Geauga, Ohio, en 1914, coincidiendo con la reestructuración del sistema de educación público de Ohio [...] Los Amish sufrieron frecuentes sentencias de multa y prisión durante las décadas de los 20 y 30 [...] Con la excepción de un caso en Pennsylvania de 1949, todas las sentencias fueron contrarias a los Amish" ${ }^{20}$. En el caso Yoder ${ }^{21}$, en cambio, el Tribunal Supremo estadounidense resolvió en su favor.

${ }^{19}$ CARPER, 2000: 16. Citado en REICH, 2002.

${ }^{20}$ Vid. RESCHLY, 2001. Los Amish de Norteamérica viven en comunidades relativamente autosuficientes, principalmente en Pennsylvania y Ontario. Sus ancestros fueron los anabaptistas europeos del siglo XVI. Rechazan el mundo contemporáneo en sus aspectos más esenciales, prefiriendo un modo de vida ascético basado en una economía agrícola o semi-agrícola de subsistencia. Su idea de la comunidad Amish como voluntaria se extiende a su trato hacia los niños. $\mathrm{Al}$ igual que otras sectas de origen anabaptista, rechazan la doctrina del baptismo infantil. Pero aunque creen que el voto del baptismo debe ser asumido voluntariamente por una persona adulta, son muy estrictos en el diseño de su sistema educativo y aculturación para asegurarse de que los niños Amish harán el voto y se unirán a la Iglesia. El sistema educativo está diseñado para preparar a los niños para su vida en la comunidad Amish, no para el mundo fuera de ella. A este objeto, tratan de proteger, ocultando, a los niños del mundo secular, y rehúsan el cuestionamiento crítico de los valores y creencias Amish. Su significada oposición a la enseñanza secundaria, la que va más allá de los 14 años, se funda en sendos motivos: primero, por cuanto ven en ella una amenaza a su completo modo de vida; y segundo, porque, sostienen, a la edad de 14 años un niño ya sabe todo lo que necesita para vivir sin problemas en su comunidad Amish. De aquí que los líderes de la comunidad Amish se hayan esforzado por mantener separadas sus comunidades de las de la sociedad moderna y hayan construido una barrera idiosincrática para protegerse de las influencias externas desarrollando una regulación y modo de vida comprehensivos que afecta a aspectos como la forma de vestir, el peinado, la decoración del hogar, la conservación del alemán y otros muchos comportamientos. Este aislamiento se conoce como Ordnung, u orden, y la separación entre lo propio de la comunidad y todo lo demás mundano el distanciamiento es uno de los principios rectores en la vida de los Amish.

${ }^{21}$ Aquí me voy a ceñir a un breve análisis del caso Yoder, porque lo que se discute en el caso Mozert v. Hawkins no es tanto la objeción a la escolarización obligatoria en sí como a determinados contenidos. 
El Fiscal del estado de Wisconsin fundó su defensa de la ley de escolarización obligatoria hasta los 16 años sobre dos argumentos. El primero, que "la educación es necesaria, en mayor o menor grado, para tomar parte efectiva y competentemente en un sistema político participativo"22. Y el segundo que la educación prepara a los individuos para una vida auto-suficiente en las sociedades modernas. Tras aceptar ambas tesis, el Tribunal desestimó la pretensión del fiscal al entender que los intereses a que servía la ley de enseñanza obligatoria de Wisconsin - preparar a los ciudadanos para una vida adulta en sociedad y autosuficiente- estaban suficientemente cubiertos por los proyectos de vida que los padres de la comunidad Amish de la Vieja Orden habían dispuesto para los menores. Al contrario de lo que parecen pensar los propios Amish, para quienes los dos años que van de los 14 a los 16 son cruciales para definir la propia identidad y las habilidades sociales, el Tribunal resolvió en favor de los padres con el argumento de que si la sentencia decidiese sustituir el programa educativo informal de la comunidad Amish por dos años adicionales de educación formal en un instituto, los intereses que pretendía satisfacer la ley de educación de Wisconsin, por lo demás legítimos, no quedarían mejor protegidos.

Aunque sea algo que ha pasado relativamente inadvertido en los análisis jurídicos acerca de la sentencia Yoder, quizá convenga apuntar que una decisión del TS estadounidense imponiendo a los Amish la enseñanza básica hasta los dieciséis años no hubiera implicado necesariamente su escolarización en un colegio público. Los Amish, como cualquier otro ciudadano, habrían podido cumplir con la legislación estatal en materia educativa matriculando a sus hijos en una escuela privada, o bien creando su propio centro docente ${ }^{23}$.

Sin embargo, la mayoría de las críticas a la sentencia del caso Yoder se han centrado en dos aspectos: por un lado, el concepto, magro, de educación democrática subyacente a la argumentación de Burger, que aparentemente se reduce a la alfabetización básica ${ }^{24}$; por el otro, que la sentencia no pondera suficientemente el derecho de los menores a una educación que tenga por objeto

${ }^{22}$ Wisconsin v. Yoder, cit., 221.

${ }^{23}$ De acuerdo, cf. ARNESON Y SHAPIRO, 1996: 388.

${ }^{24}$ Así, la sentencia afirma que los "Amish no rechazan la enseñanza elemental hasta los catorce años como principio general porque admiten que los menores han de tener unas capacidades básicas para la lectura, escritura y aritmética, con el objetivo de poder leer la Biblia, ser buenos granjeros y ciudadanos y poder relacionarse con la gente de fuera de la comunidad Amish cuando fuere necesario [...] La independencia y el buen funcionamiento social de la comunidad Amish a lo largo de casi tres siglos en total y más de 200 años en este país son una sólida evidencia de que de un período adicional de uno o dos años de educación formal obligatoria sólo cabe suponer, y ello en el mejor de los casos, una expectativa de ganancia, en términos de aprendizaje de los deberes de ciudadanía." (Cursivas mías). 
el desarrollo pleno de su personalidad ${ }^{25}$. Pues bien, precisamente en torno a estas dos cuestiones -la libertad de los padres de crear centros docentes y el derecho de los menores a una educación orientada a la formación de ciudadanos responsables capaces de participar competentemente en los asuntos de una sociedad moderna y al pleno desarrollo de su personalidad- se articula la STC 133/2010.

\subsection{La Sentencia 133/2010 del Tribunal Constitucional español}

Mediante la STC 133/2010 el TC ha resuelto por fin lo que en 1994 constituía, en opinión del Magistrado Gimeno Sendra expresada en su voto particular a la STC 260/1994, caso "Niños de Dios", el "novedoso problema de determinar si el derecho a la educación consiste en la "total libertad de los padres para orientar (a los hijos) hacia las convicciones morales, religiosas o filosóficas que crean más adecuadas a su formación intelectual y somática [...] o si dicho derecho consiste esencialmente en el derecho del niño a ser escolarizado con la consiguiente obligación de los poderes públicos de procurar dicha escolarización, incluso obligatoriamente, si ello fuera del todo punto necesario" 26 .

En 2003, el Ministerio Fiscal solicitó ante el Juzgado de Primera Instancia núm. 2 de Coín la inmediata escolarización de los hijos menores de dos familias de la localidad de Alozaina. Una maestra trabajaba con ellos con el método Montessori, y durante el juicio en Primera Instancia los padres de los tres menores argumentaron que la educación que recibían era mejor que la de los colegios públicos: hablaban cinco idiomas y recibían clases de música, matemáticas, ciencias y lengua.

El Juzgado número 2 de Coín no entró a valorar la calidad de la enseñanza. En Sentencia de 5 de mayo de 2003, ordenó a los padres demandantes de amparo que escolarizasen a sus respectivos hijos menores de edad en el ciclo escolar básico, fundamentando su decisión en que el art. $27 \mathrm{CE}$ no permite que los padres nieguen a los hijos el derecho y la obligación que tienen de participar en el sistema oficial de educación. Esta sentencia fue recurrida en apelación ante la Audiencia Provincial de Málaga, que confirmó la decisión de Primera Ins-

\footnotetext{
${ }^{25} \mathrm{Al}$ confirmar la sentencia del Tribunal de Wisconsin, el Tribunal Supremo de EEUU ratificó lo dispuesto por aquel en su mayor parte, si bien con el importante complemento conceptual del "procedimiento de ponderación" [balancing process] para resolver el conflicto de intereses entre los padres y el estado. El Tribunal Supremo estadounidense reconoció la enorme responsabilidad del estado en la educación de sus ciudadanos. "Sin embargo", escribe Burger, "el interés de un Estado en la universalidad de la educación, por más que la valoremos, no está completamente libre de un procedimiento de ponderación cuando entra en colisión con derechos fundamentales, como aquellos específicamente protegidos por el libre ejercicio de la Primera Enmienda, y el tradicional interés de los padres respecto a la educación religiosa de sus hijos."

${ }^{26}$ Apartado 2 del voto particular de Gimeno Sendra a la STC 260/1994.
} 
tancia y, a mayor abundamiento, recordó que el derecho a ser escolarizado es un derecho del menor, no de los padres, que convive con la consiguiente obligación de los poderes públicos de procurar dicha escolarización, incluso de forma obligatoria, si fuese ello necesario.

Pues bien, la cuestión central que plantea el recurso de amparo resuelto por la STC 133/2010 es la vulneración del derecho a la educación del art. 27 $\mathrm{CE}$, que los demandantes fundamentan en dos premisas. En primer lugar, se alega que la libertad de los padres para la práctica del home schooling se encuentra amparada por los arts. 27.1 (derecho de todos a la educación y libertad de enseñanza) y 27.3 (derecho de los padres a que sus hijos reciban una formación religiosa y moral que esté de acuerdo con sus propias convicciones) de la Constitución, sin que esta pretensión contravenga los mandatos en virtud de los cuales la educación debe orientarse al pleno desarrollo de la personalidad de los menores (art. 27.2 CE) y, además, será obligatoria y gratuita (art. 27.4 CE). En segundo término, los demandantes alegan que en el caso del home schooling nos encontraríamos ante una "laguna legislativa", pues las leyes educativas sólo prevén la enseñanza en centros docentes (primer inciso del FJ 4). Estudiaré el análisis que hace la STC 133/2010 de ambos argumentos en orden inverso.

En efecto, una de las alegaciones recurrentes de los defensores del home schooling en España es que la Constitución de 1978 no protege la obligatoriedad de la escolarización, sino tan sólo el derecho a la educación dentro de unos valores constitucionales, y que conviene no confundir la educación con la escolarización, ya que lo uno no implica lo otro ${ }^{27}$. Sin embargo, como he dicho anteriormente (apartado 2.1) y señala el TC en su sentencia, tanto el art. 9 LOCE como el vigente art. 4.2 LOE establecen que la enseñanza básica, además de ser obligatoria y gratuita, incluye diez años de escolaridad y se desarrolla, de forma regular, entre los seis y los dieciséis años de $\operatorname{edad}^{28}$. La conducta de los padres consistente en no escolarizar a los menores, es decir, el home schooling, es por consiguiente una práctica en sí misma antijurídica, sin que quepa hablar de laguna normativa de ningún tipo (STC 133/2010, FJ 4 , inciso segundo).

Dicho esto, el Tribunal pasa a analizar si el deber de escolarización impuesto legalmente es o no respetuoso con el derecho fundamental a la educación alegado por los padres. $\mathrm{O}$, dicho de otra forma, si la práctica del home schooling viene amparada por alguna de las libertades constitucionales que el art. $27 \mathrm{CE}$ reconoce.

${ }^{27}$ Cf. MARTÍ SÁNCHEZ, 2010.

${ }^{28}$ En congruencia con la Ley Orgánica 1/1996, de 15 de enero, de Protección Jurídica del Menor, cuyo artículo 13.2 asigna a "cualquier persona o autoridad que tenga conocimiento de que un menor no está escolarizado o no asiste al centro escolar de forma habitual y sin justificación, durante el periodo obligatorio", el deber de "ponerlo en conocimiento de las autoridades públicas competentes, que adoptarán las medidas necesarias para su escolarización". 
No lo está, en primer lugar, en la libertad de enseñanza del art. 27.1 CE de los padres, pues, por lo que se refiere a la enseñanza básica, ésta se circunscribe a la facultad de enseñar libremente fuera del horario escolar, sin perjuicio, eso sí, de su deber de escolarización, de una parte, y de la libertad de creación de centros docentes del art. 27.6 CE, de otra, cauce específico del ejercicio de la libertad de enseñanza de los padres en esta etapa de la educación (FJ 5).

Tampoco lo está en el derecho de todos a la educación del art. 27.1 CE, que en lo que se refiere a la determinación por los padres del tipo de educación que habrán de recibir sus hijos se limita, de acuerdo con la doctrina del $\mathrm{TC}^{29}$, al reconocimiento de una libertad de los padres para elegir centro docente y al derecho de éstos a que sus hijos reciban una formación religiosa y moral que esté de acuerdo con sus propias convicciones (art. 27.3 CE), un derecho éste que, por las razones que ya han quedado expuestas (apartado 2.4), el TC mantiene que "no se ve comprometido en el presente supuesto" (FJ 5).

Pero además de por esta razón, la imposición legal del deber de escolarización constituye un límite constitucionalmente viable a la autoridad de los padres en la educación de los menores por compadecerse bien con el mandato en virtud del cual los poderes públicos deben "garantiza[r] el derecho de todos a la educación mediante la programación general de la enseñanza" (art. 27.5 $\mathrm{CE}) \mathrm{y}$, además, con el objetivo que la $\mathrm{CE}$ ha atribuido a la enseñanza y al sistema educativo en que ésta se realiza y que lejos de limitarse a la mera transmisión de conocimientos, se propone "el pleno desarrollo de la personalidad humana en el respeto a los principios democráticos de convivencia y a los derechos y libertades fundamentales" (art. 27.2 CE). En contra de las alegaciones de los padres de que la imposición de la escolarización obligatoria como sinónimo de enseñanza obligatoria, primero, "no supera el juicio de indispensabilidad", por cuanto "del análisis de las legislaciones de países de nuestro entorno sociocultural se deduce claramente que existen reglas que permiten conciliar, de mejor manera, los distintos intereses en juego", y segundo, vulnera el principio de proporcionalidad en sentido estricto, por entender que "las ventajas que se obtienen con la limitación del derecho [no son] superiores a los inconvenientes que se producen en este caso para los titulares de la libertad de enseñanza", teniendo en cuenta que en él "los padres, lejos de hacer dejación de sus deberes, se esfuerzan por ofrecer a sus hijos una formación más específica e individualizada", el TC sostiene que ambos planteamientos han de ser rechazados. En cuanto a lo primero, porque incluso si se estuviera de acuerdo en que la medida alternativa (a la escolarización) de un home schooling sometido a controles administrativos sobre los contenidos de la enseñanza y evaluaciones periódicas de los resultados efectivamente obtenidos por los menores, constituye un medio menos restrictivo que la imposi-

${ }^{29}$ Cf. ATC 382/1996, de 18 de diciembre, FJ 4. 
ción del deber de escolarización, sin embargo ésta no es la única finalidad que deben perseguir los poderes públicos a la hora de diseñar el sistema educativo en general y la enseñanza básica en particular, "que han de servir también a la garantía del libre desarrollo de la personalidad individual en el marco de una sociedad democrática y a la formación de ciudadanos respetuosos con los principios democráticos de convivencia y con los derechos y libertades fundamentales, una finalidad ésta que se ve satisfecha más eficazmente mediante un modelo de enseñanza básica en el que el contacto con la sociedad plural y con los diversos y heterogéneos elementos que la integran [...] forma parte de la experiencia cotidiana que facilita la escolarización" (FJ 8). Y en cuanto a lo segundo, porque "el alcance de la restricción operada en el contenido protegido por el derecho de los padres reconocido en los arts. 27.1 y 3 $\mathrm{CE}$ ha de ser en todo caso relativizado en la medida en que [...] no impide a estos influir en la educación de sus hijos, y ello tanto dentro como fuera de la escuela", pero, sobre todo, en tanto que los padres "pueden ejercer su libertad de enseñanza a través del derecho a la libre creación de centros (art. 27.6 CE)" (FJ 8, in fine). Era ésta, concluye la ponente de la sentencia, María Emilia Casas Baamonde, y no el incumplimiento del deber de escolarizar a los menores, la opción constitucional disponible para los padres para dar cauce a sus distintas convicciones morales, religiosas o pedagógicas.

Una interpretación por lo demás coincidente con la STC 260/1994, caso "Niños de Dios", que si bien denegó el amparo a la Generalitat Catalana sobre la base de que los Autos de la Audiencia Provincial de Barcelona allí recurridos no impidieron la escolarización de facto de los menores, estableció que ello ha de entenderse "sin que en modo alguno se desprenda de sus partes dispositivas que la Generalidad no pueda servirse de los instrumentos de los que legalmente está dotada para hacer efectiva la escolarización a la que todo menor tiene derecho y a cuya verificación vienen obligados quienes de ello son responsables" (STC 260/1994, de 3 de octubre, FJ 2 in fine).

En definitiva, la STC 133/2010 es un buen ejemplo de la aplicación práctica de la correcta teoría y zanja el conflicto de intereses entre la voluntad de los padres (cuya pretensión es subsumir el derecho a la educación dentro de un supuesto derecho a la no escolarización) y los intereses de los menores que la anterior jurisprudencia constitucional había dejado sin resolver ${ }^{30}$. Esta correcta teoría descansa en dos premisas, que aparecen en los FFJJ 6 y 7 de la STC 133/2010:

a) La correcta delimitación del contenido del derecho a la educación -en sus vertientes libertad de enseñanza y a que los hijos reciban la formación religiosa y moral que esté de acuerdo con sus propias convicciones- conduce a negar que la imposición del deber de escolarización alcance la relevancia constitucional, por lo que, en opinión del Tribu-

${ }^{30}$ Cf. STC 5/1981 y 260/1994. 
nal, la libertad religiosa no ampara un supuesto derecho de los padres a la no escolarización de los hijos.

b) Aun cuando la decisión de no escolarizar a los menores estuviera motivada por razones de orden moral o religioso y por tanto amparada por el art. 27.3 CE, el período de escolarización obligatoria incorporado por el legislador constituye un límite a la autoridad de los padres en la educación de los menores constitucionalmente justificable por estar de conformidad con otras disposiciones constitucionales contenidas en el propio art. 27 y con la finalidad que en su apartado 2 se le atribuye a la educación, que tendrá por objeto el pleno desarrollo de la personalidad del menor.

\section{LÍMITES A LA AUTORIDAD DE LOS PODERES PÚBLICOS: ES- COLARIZACIÓN OBLIGATORIA Y EL PRINCIPIO LIBERAL DE NEUTRALIDAD ESTATAL}

\subsection{Algunas precisiones previas sobre la tesis liberal de la neutralidad del Estado}

En el debate sobre las relaciones entre la tesis de la neutralidad del Estado liberal y la escolarización obligatoria nos encontramos con un problema serio, y es que el uso del mismo concepto de neutralidad quizá contribuye a enturbiar más que a aclarar la discusión. Haré, pues, cuatro precisiones sobre la tesis de la neutralidad ${ }^{31}$. Aunque las cuestiones conceptuales se hallan siempre conectadas con los problemas de justificación y es quizá engañoso tratar de distinguirlas, me inclino a creer que "tienen una cierta prioridad lógica sobre ellos" 32 , por lo que comenzaré por aquéllas.

Una primera precisión sobre el significado de la tesis de la neutralidad se refiere al ámbito de las decisiones implicadas. La tesis desde luego no hace a las decisiones de los ciudadanos en su vida personal o en tanto individuos privados, sino a los ciudadanos en tanto actores de la vida política colectiva o en la comunidad política. No sólo sería contraintuitivo sino además absurdo pedir a los ciudadanos que el principio de neutralidad entre distintas concepciones del bien que aplican en sus relaciones con el resto de los ciudadanos lo hagan extensivo a su vida familiar.

En segundo lugar, y al hilo de lo anterior, son precisamente los factores distintivos de la asociación política, en tanto que asociación no voluntaria, y de la acción del Estado, en cuanto que acción coercitiva, los que explican la limitación anterior. Pero entonces surge la cuestión de si sólo las legislaciones penal y fiscal se ven afectadas por la restricción neutralista o, por el contrario, ésta afecta también a los otros medios por los que los poderes públicos

\footnotetext{
${ }^{31}$ Sobre esta cuestión, véase COLOMER, 1998.

${ }^{32}$ Cf. LAPORTA, 1987.
} 
desincentivan o alientan determinadas acciones individuales. Creo que, aun difiriendo en aspectos relevantes de las sanciones penales o fiscales, en la medida en que los métodos de influencia que el Estado aplica en el ámbito sanitario, educativo o social interfieren en los contextos de decisión individual aumentando o restringiendo las opciones, el principio de neutralidad debe regir también en esas otras esferas. Ahora bien, la intensidad con que dicha tesis opera debe modularse en función de quienes, en cada ámbito, son destinatarios de la acción de los poderes públicos.

Además, una tercera posibilidad de delimitación de la tesis liberal de la neutralidad se refiere a la distinción entre la llamada neutralidad de efectos o resultados de la acción del Estado y la neutralidad de propósitos o en la justificación de tal acción. Según la primera, más restrictiva, los poderes públicos han de ser imparciales entre todas las concepciones de la vida buena, deviniendo ilegítima toda política pública que tenga como efecto el favorecimiento o la obstaculización de algunas de ellas. La segunda, y que creo más viable, establece al Estado el límite, menos oneroso, de ser imparcial entre las distintas concepciones de la vida buena o bien, en una versión ligeramente diferente, de excluir dichas nociones del proceso de toma de decisiones políticas.

Por último, como afirma acertadamente Neil MacCormick, "la cuestión en disputa no es si debería utilizarse el poder del [E]stado de acuerdo con principios morales, sino qué principios morales deben observarse en ese ejercicio". El principio liberal de neutralidad es en este sentido un principio moral que prescribe, en tanto que moralmente valioso, que el poder del Estado "no se utilice para implantar valores morales"33. Pero según añade además Waldron, este principio de neutralidad no se configura como valor último, sino como consecuencia de otros valores de la moral política que serán así los que determinen su alcance ${ }^{34}$. Lo que propone la tesis liberal no sería una neutralidad absoluta, sino sólo entre concepciones del bien a las que los ciudadanos pueden adherirse haciendo uso de su autonomía.

Dicho esto, uno de las primeros en comentar críticamente la STC 133/2010 ha sido Rafael Navarro-Valls, en un artículo en prensa intitulado "La educación en casa o cuando el Estado invade la vida privada de sus ciudadanos" ${ }^{35}$. Para Navarro-Valls, el sistema de escolaridad obligatoria está sufriendo un doble ataque: por un lado, el de aquellos que en el plano teórico lo

${ }^{33}$ Cf. MacCORMICK, 1990: 92.

${ }^{34}$ Cf. WALDRON, 1993.

${ }^{35}$ NAVARRO-VALLS, 2010. El artículo ha sido muy difundido en Internet por los defensores del home schooling en España. Así, por ejemplo, se puede visitar en las siguientes direcciones: http://derechoyfactoreligioso.blogspot.com/, http://madalen.wordpress.com/ $\mathrm{s}=$ navarro, o http://www.objetores.org/2010/12/la-educacion-en-casa-o-cuando-el-estadoinvade-la-vida-privada-de-sus-ciudadanos/. 
tachan de grave intromisión del Estado en la vida privada de los ciudadanos, por ejemplo Milton Friedman, y, por otro lado, el de las asociaciones estadounidenses, inglesas, francesas o españolas de padres que postulan como alternativa el home schooling. Creo que ese "doble ataque" refleja bien, aunque mezclados, porque a menudo también lo están las posturas de quienes los sostienen, los dos argumentos más utilizados por quienes se oponen a la escolarización obligatoria, por lo que, siguiendo parcialmente la argumentación de Navarro-Valls, estructuraré este apartado en tres secciones. En las dos primeras examinaré las críticas que desde el liberalismo económico y el comunitarismo se han venido realizando a la escolarización obligatoria mediante la invocación de los valores de la libertad de mercado y la autonomía de la familia. Anticipo que ninguno de estos dos argumentos contra la obligatoriedad de la escolarización me parecen lo suficientemente fundados como para motivar su oposición, y que la única objeción viable es la que, tomándose en serio los derechos del niño, se plantea desde el liberalismo político (apartado 4.4.).

\subsection{La crítica a la escolarización obligatoria de los teóricos del libre mer- cado: el enfoque del minimalismo educativo}

Del título elegido para su artículo se desprende sin demasiada dificultad que Navarro-Valls comparte la visión friedmaniana del papel que el Estado ha de tener en la educación. En 1955 Friedman publicó un artículo que tuvo una gran repercusión en la época en el que reflexionaba sobre el papel de los poderes públicos en la educación ${ }^{36}$. En un contexto, el de la década de los 50, caracterizado por la tendencia a incrementar la intervención del Estado en la economía estadounidense, Friedman se propone reconsiderar los límites de la autoridad del Estado en el ámbito específico de la educación. Aunque quizá resulte prolijo, creo que, debido a su influencia, conviene exponer brevemente sus tesis acerca del correcto diseño del sistema educativo.

En su artículo, Friedman comienza asumiendo que en una economía de libre intercambio entre empresas privadas, el papel del Estado se reduce a preservar las reglas del juego haciendo cumplir los contratos, evitar la coerción y mantener la libertad de los mercados. Más allá de esto, sólo existen tres casos en que la intervención del poder público está justificada. Uno es el monopolio "natural" u otras imperfecciones similares del mercado que hacen la competencia imposible. Otro es la existencia de externalidades, esto es, la acción de un individuo que impone costes o ganancias significativos y difícilmente compensables sobre otros, circunstancia que de nuevo entorpece el ejercicio del libre intercambio. La tercera se relaciona con la preocupación paternalista por los niños y otros agentes incapaces de asumir responsabilidades o gobernarse a sí mismos, pues la creencia en la libertad se predica tan

\footnotetext{
${ }^{36}$ Cf. FRIEDMAN, 1955.
} 
solo de aquellos individuos capaces de responsabilidad y agencia moral, entre quienes no cabe incluir ni a los menores ni a los enfermos mentales.

Así pues, la injerencia de los poderes públicos en la educación, imponiendo el requerimiento de un nivel mínimo de educación cuya financiación corre a cargo del Estado, sólo está justificada por cuanto es imposible la conformación de una sociedad democrática estable sin la amplia aceptación de un conjunto compartido de valores y sin un grado mínimo de alfabetización de la mayoría de la ciudadanía. Dicho de otra forma: en la visión friedmaniana de la educación, la intervención de los poderes públicos se justifica sólo por sus externalidades positivas, en la medida en que la acción del Estado sobre los menores aumenta el bienestar de otros agentes (el resto de la sociedad) de la economía ${ }^{37}$.

Ahora bien, que Friedman justifique cierta presencia gubernamental en la educación no significa que admita la garantía de su asunción por los poderes públicos, en aras de hacer efectivo el derecho de todos los ciudadanos a la educación. Más que hacerse cargo de la financiación y administración de un complejo sistema educativo, Friedman cree que el Estado ha de conceder prestaciones en efectivo (cheques) a los padres con hijos menores a su cargo, y garantizar así la libertad de elección de éstos entre los distintos tipos de escuela: pública, privada o religiosa ${ }^{38}$. Un acuerdo de esta clase haría más efectiva la competencia entre los varios tipos de escuela, igualaría los recursos de que disponen y eliminaría la discriminación a favor de la escuela pública ${ }^{39}$.

Desde este "minimalismo educativo", como señala Amy Gutmann, la exigencia de "algo más que el mínimo de civismo constituye un ejercicio ilegítimo de autoridad política sobre una parte de la ciudadanía y, en consecuencia, debería estar prohibido por la Constitución", por lo que reclaman "menos autoridad estatal sobre la escolarización"; así, el "corolario habitual es la defensa de la elección del tipo de escuela de los padres, con frecuencia a través de un sistema de [cheques]" ${ }^{40}$. Pues bien, de este enfoque minimalista con su

${ }^{37}$ En la biblioteca de Economía Econlib, Bryan Caplan define las externalidades positivas como "los beneficios o las ventajas de imposible valoración y que, por ello, no resultan compensadas." Visítese el sitio web: www.econlib.org/library/Enc/Externalities.html. (Consultado por última vez el 14/01/2011).

${ }^{38}$ Friedman parece admitir la existencia, en todo caso condicionada, de alguna forma de educación pública, al afirmar que "las escuelas públicas que se mantengan deberían cobrar alguna clase de cuota para cubrir los costos de la educación de los alumnos, lo que las igualaría a la hora de competir con las escuelas del sector privado".

${ }^{39}$ Aunque el origen remoto del mecanismo de los cheques escolares (school vouchers) se encuentra en dos programas escolares de los estados de Vermont y Maine, que comenzaron en 1869 y 1873 respectivamente, su recuperación y rediseño por Friedman en 1955 provocó que en la década de los ochenta Chile, Gran Bretaña y la Administración Reagan los reimplantaran y, a partir de entonces, los defensores del "minimalismo educativo" los propongan como solución a casi cualquier problema educativo.

${ }^{40}$ GUTMANN, 2001: 358 . 
consiguiente propuesta de reforma de la financiación del sistema educativo, es del que mutatis mutandis parten los defensores del home schooling en su crítica al modelo español de escuela. En efecto, para José María Martí Sánchez,

"No se puede supeditar el nivel de ayudas recibidas a que, el derecho de elección, se ejerza en una u otra dirección. Lo importante es salvar la calidad de la enseñanza. Otra cosa sería penalizar determinadas opciones. En ciertos países -concretamente, algunas provincias de Canadá- se otorga una financiación a los padres del homescooling." ${ }^{41}$

Centrándonos por ahora en el "corolario" del modelo de financiación que exige el enfoque minimalista, y a pesar de que Gutmann ya alertó en su libro Democratic Education de que el hecho de que una enmienda constitucional necesite un respaldo democrático "le crea un verdadero problema al minimalismo cívico" "42, ésta es precisamente la vía por la optaron en 2009 en EEUU, mediante la presentación de sendos proyectos legislativos que aún no han sido aprobados: de una parte, la Ley de Libertad de Educación Familiar, que proponía una deducción fiscal de hasta 5.000 dólares para los padres que optaran por la escuela privada o el home schooling; de otra, la propuesta de enmienda constitucional conocida como de los "Derechos de los Padres", redactada por Michael Farris, fundador de la Asociación Legal para la Defensa del Home School, y que de ser adoptada protegería "la libertad de los padres para dirigir la educación y crianza de sus hijos" como un derecho fundamen$\mathrm{tal}^{43}$. Ahora bien, de aprobarse finalmente por la nueva mayoría en la Cámara de Representantes, la nueva enmienda de los Derechos de los Padres dificultaría la ratificación de EEUU de la CDN, de la que actualmente son Estados parte 192 países y solamente dos, EEUU y Somalia, no han ratificado aún ${ }^{44}$. Por una parte, limitaría la capacidad del gobierno de regular la educación en casa y, por otra, significaría la transferencia de hasta cinco mil dólares a las familias que decidieran participar en un sistema privado de home schooling impermeable a la fiscalización de los poderes públicos o, cuando menos, opaco $^{45}$.

En España, un estudio realizado por la Fundación de Cajas de Ahorros (Funcas) sobre La experiencia valenciana concluye que los resultados de la "introducción del cheque escolar tras las elecciones de 1991" no cumplieron "los dos objetivos" de "igualdad de oportunidades" y de "libertad de elección

${ }^{41}$ MARTÍ SÁNCHEZ, 2010: 6-7.

${ }^{42}$ GUTMANN, 2001: 360.

${ }^{43}$ Cf., HUERTA, 2011.

${ }^{44}$ Véase, por ejemplo, el sitio web de Unicef: http://www.unicef.org/spanish/ crc/index_30229.html (Consultado por última vez el 25/01/2011).

${ }^{45}$ Cf. L. Huerta, cit. 
de centros", ante la nula oferta pública existente. Al contrario, el cheque escolar se puede calificar "como un sistema de financiación de la educación privada", en el que los pobres resultados son directamente atribuibles a la "escasez de regulaciones" 46 .

Y es que, en definitiva, no debería ser necesario seguir recordando que el enfoque que entiende la relación entre derecho y libertad de forma tal que el derecho es, necesariamente, restricción de la libertad, adolece del problema fundamental de que desconoce que el derecho es condición, y no ya sólo limitación, de la libertad ${ }^{47}$. La tesis de la neutralidad liberal sostiene, efectivamente, que no es tarea del Estado promover la particular visión que del sistema democrático tengan sus ciudadanos, sea ésta patriótica, conservadora o socialista, sino que lo es proteger sus derechos. Pero esto no supone, como pretenden los teóricos del laissez faire o libre mercado, limitar aquellos derechos a los de libertad y propiedad, pues la tesis liberal de la neutralidad del Estado es decididamente compatible, como lo muestran las obras de autores de la influencia de Ronald Dworkin, Thomas Nagel o John Rawls ${ }^{48}$, con los valores de igualdad, seguridad y, en lo que aquí nos interesa, la prestación por los poderes públicos de servicios como la educación o la sanidad.

\subsection{La crítica comunitarista: autonomía de la familia y objeción de con- ciencia}

El otro ataque a la escolarización obligatoria procede de las asociaciones de padres de diversos países que defienden la alternativa del home schooling. Respecto a este punto, Navarro-Valls sostiene que "educación no es sinónimo de escolarización”, por lo que el home schooling no sólo debería permitirse, pues "la entidad de la libertad fundamental en juego (autonomía de la familia) no admite su limitación por simples razones de eficiencia, bienestar o igualdad", sino que además debería también regularse, ya que el "hecho de que el home schooling se encuentre regulado responde a la preocupación razonable y legítima del Estado por asegurar un mínimo de eficacia en cuanto a los contenidos de la educación [...]"49. En cuanto a esto último, baste ahora con observar, como hace la STC 133/2010, que esta posición centra excesivamente el foco en la enseñanza como la simple transmisión de conocimientos, obviando los objetivos que la $\mathrm{CE}$ y los tratados y convenciones internacionales atribuyen a la educación a la que, conviene recordarlo, los

\footnotetext{
${ }^{46}$ Cf. GRANELL-PÉREZ, 2010.

${ }^{47}$ Vid. COLOMER, 1998: 89.

${ }^{48}$ Esto es así hasta el punto de que en la teoría de Rawls los llamados "bienes primarios" -derechos, libertades, ingresos y riqueza- son repartidos entre todos los ciudadanos de forma equitativa, en el entendimiento de que son necesarios para la realización de cualquier concepción del bien.

${ }^{49} \mathrm{Cf}$. NAVARRO-VALLS, cit.
} 
niños tienen derecho. Pero más allá de esto, lo que me interesa discutir en esta sección es la categoría de "nuevos objetores" que Navarro-Valls atribuye a los padres defensores del home schooling ${ }^{50}$.

Una crítica habitual a la imposición de la escolarización obligatoria es que se trata de una medida que invade el ámbito de la autonomía familiar y no respeta las convicciones personales de los menores y/o de sus padres, por lo que constituiría uno de los supuestos en que cabe la objeción de concien$\mathrm{cia}^{51}$. La crítica de fondo desde esta perspectiva comunitarista es que los liberales asumen de un modo un tanto ingenuo que los individuos van a adquirir efectivamente un cierto compromiso general de justicia y libertad para todos -compromiso que, entendido como una de las facultades morales de los ciudadanos en tanto que personas, es, para Rawls, necesario para la existencia de una sociedad bien ordenada-, minusvalorando sistemáticamente la importancia de un marco valorativamente denso de contenidos culturales, afectivos o éticos compartidos ${ }^{52}$.

Pues bien, la objeción de conciencia a la escolarización obligatoria resulta, como ha afirmado el TC sobre nuestro tema en la STC 133/2010, "constitucionalmente inobjetable" 53 . Esta conclusión insiste en la argumentada prioridad de la autonomía de los menores frente a una abusiva demanda parental de reclusión social y duplicación ideológica: si la autonomía es la "condición de quien, para ciertas cosas, no depende de nadie" ${ }^{54}$, una contingencia que los poderes públicos han de evitar es que los niños sean educados de forma que se les blinde frente al mundo exterior. Ésa es precisamente la pretensión de las comunidades Amish, tal como se reconoce en la propia sentencia del caso Yoder, que pudo resolverse a favor de los padres sólo en la medida en que el Tribunal Supremo estadounidense no incluyó los intereses derivados del derecho a la educación del menor en su ponderación. Como afirma el juez William O. Douglas en su voto particular a la sentencia del caso Yoder, el menor

${ }^{50}$ Así, por ejemplo, cuando escribe: "Estos “nuevos objetores" no plantean eludir la obligación de educar a sus hijos, sino que rehúsan aceptar que la escuela sea el único y excluyente medio de conseguir ese objetivo."

${ }^{51}$ Para José María Martí Sánchez, por ejemplo, es posible establecer una división de las objeciones de conciencia en el ámbito educativo en tres bloques; los dos primeros, de carácter más general o difuso, estarían formados por las objeciones que se dirigen contra la obligatoriedad del sistema público de educación, el primero, y contra normas disciplinarias académicas, el segundo. En el tercero se encuadrarían las objeciones contra alguno de los elementos del currículo obligatorio, como gimnasia, música, educación sexual, educación para la ciudadanía, etc. (Vid. MARTÍ SÁNCHEZ, 2007).

${ }^{52}$ Para una posición radicalmente distinta dentro del enfoque comunitarista, vid. ETZIONI, 2002.

${ }^{53} \mathrm{Cf}$. FJ 9, in fine.

${ }^{54}$ Diccionario de la Real Academia Española (DRAE), vigésima segunda edición. Consultado en la dirección de Internet: http://www.rae.es/rae.html 
"puede querer convertirse en pianista, astronauta u oceanógrafo. Pero para conseguirlo tendrá que desvincularse de la tradición Amish. Es el futuro del menor, no el futuro de los padres, lo que está en juego. Si unos padres no permiten a su hijo continuar en la escuela más allá de la educación primaria, entonces al niño se le impedirá para siempre el acceso al nuevo y sorprendente mundo diverso que tenemos hoy." 55

Una respuesta distinta a la crítica comunitarista sería la empleada recientemente por la Abogacía del Estado al oponerse al recurso de inconstitucionalidad formulado por los padres de una niña contra la obligatoriedad de la enseñanza de la asignatura de "Educación para la Ciudadanía", después de que el TS anulara una sentencia del Tribunal Superior de Justicia de Castilla y León que resolvió a favor de los padres ${ }^{56}$. Haciendo uso del conocido argumento de la pendiente resbaladiza ${ }^{57}$, el Abogado del Estado aduce que en este caso la objeción recae sobre la Educación para la ciudadanía, "pero mañana podría objetarse Ciencias de la Naturaleza porque se explica la teoría de la evolución, incompatible con la letra del relato bíblico de la creación". En efecto, una vez aceptada la objeción a la escolarización obligatoria, la propia enseñanza básica podría ser también susceptible de objeción por razones de conciencia.

Si los argumentos del juez Williams y de la Abogacía del Estado son ciertos, entonces a los padres no les cabe la objeción a la escolarización obligatoria. Ahora bien, que ello sea así no significa que el Estado, en su regulación del sistema educativo, no se haya deslizado por otra pendiente resbaladiza, en este caso la de un perfeccionismo ético de base liberal kantiana.

\subsection{La objeción del liberalismo pluralista: autonomía del menor, diver- sidad y tolerancia}

Una última crítica a la escolarización obligatoria, proveniente del liberalismo pluralista ${ }^{58}$, apunta a que se trata de una medida que, al justificarse desde las premisas insuficientemente imparciales del liberalismo moral y en su principio de autonomía personal, quiebra la tesis de la neutralidad liberal. En tal sentido, William Galston ha argumentado que, en casos como el de Yoder, el Estado liberal no debería actuar, en tanto que con su intervención podría so-

${ }^{55}$ Wisconsin v. Yoder, 406 U.S. 205 a 236, 1972.

${ }^{56}$ LÁZARO, 2010.

${ }^{57}$ En el mismo sentido, vid. RUIZ MIGUEL, 2007: 18". Y en relación con esto, en la bibliografía hacer constar, mediante guión, un segundo trabajo de RUIZ MIGUEL, Alfonso (2007): "Educación, escuela y ciudadanía", en A. López Castillo (Ed.), Educación en valores. Ideología y religión en la escuela pública, Madrid, Centro de Estudios Políticos y Constitucionales, pp. 27-49..

${ }^{58}$ Véase, por ejemplo, WILLIAMS, 1981; RAZ, 1983; TAYLOR, 1982; GRAY, 1996. 
cavar valores que son necesarios para la continuidad de ciertas comunidades basadas en doctrinas comprehensivas ${ }^{59}$. Los defensores de la tesis de la neutralidad han dado dos tipos de respuesta a esta objeción, que a su vez emergen de sendas corrientes de pensamiento liberal basadas en los principios de autonomía y tolerancia.

Desde un liberalismo más o menos comprehensivo, la neutralidad tiene una importancia exclusivamente instrumental o derivada de otros valores morales o políticos, que en este caso sería el principio de autonomía personal ${ }^{60}$. Pues bien, desde un liberalismo explícitamente kantiano, Victoria Camps afirma que

"Que la educación debe estar comprometida con unos valores éticos es una afirmación difícilmente discutible [...] Educar es, así, formar el carácter para que se cumpla un proceso de socialización imprescindible [...] Y para formar el carácter no hay más remedio que inculcar unos valores." ${ }^{1}$

Para este liberalismo kantiano la crítica pluralista estaría, en primer lugar, mal planteada. Según se precisó antes, la tesis liberal no sostiene, ni pretende sostener, una neutralidad absoluta, sino sólo entre diversas concepciones del bien. A partir de aquí, la intervención del Estado para imponer legalmente la escolarización obligatoria puede fundarse en las siguientes tres razones: primero, como forma de proporcionar a los menores una posibilidad efectiva de salida (de la comunidad de origen), y que de otra manera tendrían denegada por la falta de educación ${ }^{62}$; segundo, como medio de asegurar que los niños tengan los suficientes recursos intelectuales como para participar en los procesos que se desarrollan en el marco de una sociedad democrática y plural ${ }^{63}$; y, por último, para proteger el derecho del menor a un futuro abierto, en el que la elección entre las diversas concepciones del bien se produzca autónomamente.

Otros como John Rawls o Thomas Nagel, en cambio, aceptando en cierto sentido el valor de la crítica del liberalismo pluralista, han rediseñado las exigencias de la tolerancia en sus teorías de la justicia para que la tesis de la neutralidad que se recoge en ellas sea asumible por ciudadanos que mantienen

\footnotetext{
${ }^{59}$ GALSTON, 1995: 533.

${ }^{60}$ Ejemplos de este liberalismo comprehensivo de la autonomía son la obra de Kant, Mill o Locke. Sobre la existencia de un liberalismo perfeccionista comprometido con una concepción del bien centrada en la idea de autonomía, vid. COLOMER, 2001, donde se hace un repaso de esta corriente, con especial atención a las tesis de J. Raz.

${ }^{61}$ CAMPS, 1994: 11.

${ }^{62}$ OKIN, 2002.

${ }^{63}$ Cf. GALSTON, 2002.
} 
posiciones diferentes al liberalismo de la autonomía ${ }^{64}$. En un paso del Liberalismo político referido específicamente a la educación, Rawls confirma su distancia respecto del liberalismo moral kantiano al afirmar que el liberalismo político aceptaría sólo que "la educación de los niños incluyera cosas tales como el conocimiento de sus derechos constitucionales y civiles", si bien "debería también estimular en ellos las virtudes políticas" ${ }^{\circ 5}$.

Esta posición del estricto liberalismo político de Rawls -en el que la tolerancia sería un punto intermedio entre los valores de la autonomía y la diversidad-, resulta, me parece, inestable. Y ello porque no tiene suficientemente en cuenta que, como se dijo antes, la intensidad con la que opera la tesis de la neutralidad es diferente en función de cuál sea el ámbito de la acción de los poderes públicos. Seguramente sea verdad, como defiende Nagel, que "la posición verdaderamente liberal está comprometida con el rechazo a utilizar el poder del Estado para imponer paternalistamente a sus ciudadanos una concepción individualista de la vida buena" ${ }^{66}$, pero en la educación, donde el Estado no trata, como en el terreno fiscal, con contribuyentes adultos, sino con estudiantes menores, la acción de los poderes públicos para imponer a los padres la escolarización de sus hijos se limita a garantizar que la elección de los jóvenes de sus propios ideales y planes de vida será libre, autónoma y entre diferentes concepciones del bien.

\section{BIBLIOGRAFÍA}

ARNESON, Richard J. y SHAPIRO, I. (1996): "Democratic Autonomy and Religious Freedom: A Critique of Wisconsin v. Yoder", en NOMOS XXXVIII: Political Order, Ian SHAPIRO y Russell Hardin (Eds.), Nueva York, New York University Press, pp. 365-411.

Brooks, Samuel D. (1990): “Native American Indians' Fruitless Search for First Amendment Protection of Their Sacred Religious Sites", Valparaíso University Law Review, núm. 24, pp. 521-551.

Callan, Eamonn (1997): Creating Citizens. Political Education and Liberal Democracy, Oxford, Clarendon Press.

\footnotetext{
${ }^{64}$ Cf. NAGEL, 1991; RAWLS, 1996. En “Two Concepts of Liberalism” Galston confronta dos visiones distintas del liberalismo, basadas en los valores de la autonomía y la diversidad, y sostiene además que la disputa entre ambos conceptos no es azarosa ni característica de la teoría política contemporánea, sino que tiene su origen en el desarrollo histórico del liberalismo, de tal forma que mientras la autonomía está vincula al impulso histórico del proyecto de la Ilustración, la diversidad liberal lo está al de la Reforma protestante. Creo, en cambio, que es preferible hablar de tolerancia antes que de "diversidad" pues ésta, si no va acompañada de otros valores como el respeto, la libertad o, en definitiva, la tolerancia, no constituye un principio moral por sí mismo. Aunque sin detenerme en ello, diré que creo que esta cuestión es precisamente la que separa al liberalismo pluralista del político: mientras el primero se justifica desde el valor de la diversidad, el segundo lo hace desde el de la tolerancia.
} 
CAMPS, Victoria (1994): Los valores de la educación, Madrid, Anaya.

CARPER, James C. (2000): "Pluralism to Establishment to Dissent: The Religious and Educational Context of Home Schooling", Peabody Journal of Education, núm. 75, pp. 8-19.

Colomer, José Luis (1998): "Libertad personal, moral y derecho. La idea de la "neutralidad moral" del Estado liberal", en Anuario de la Facultad de Derecho de la Universidad Autónoma de Madrid, núm. 2, pp. 89-129.

ETZIONI, Amitai (2002): "A Communitarian Position on Character Education", en W. Damon (Ed.), Bringing in a New Era in Character Education, Stanford, Hoover Institution Press, pp. 113-29.

Friedman, Milton (1955): "The Role of Government in Education", en R. A. Solo (Ed.), From Economics and the Public Interest, Nueva Jersey, Rutgers College.

Galston, William (1995): “Two Concepts of Liberalism”, Ethics, núm. 105, pp. 516-34.

-(2002): "Parents, Government, and Children: Authority over Education in the Liberal Pluralist State", en Liberal Pluralism. The Implications of Value Pluralism for Political Theory and Practice, pp. 93-109.

Gordon, James D. (1996): “Wisconsin v. Yoder and Religious Liberty”, Texas Law Review, núm. 74, pp. 1237-1240.

Granell PÉrez, Rafael (2010): “Los bonos educativos en España: la experiencia valenciana", en Financiación de la enseñanza obligatoria: los bonos escolares en la teoría y en la práctica, Madrid, Fundación Funcas. GrAY, John (1996): Isaiah Berlin, Princeton, NJ, Princeton University Press. Gutmann, Amy (1995): "Civic Education and Social Diversity", Ethics, núm. 105, pp. 557-79.

-(1999): Democratic Education, Princeton, N. J., Princeton University Press ( $1^{a}$ ed. 1987); trad. cast. de Águeda Quiroga, Barcelona, Paidós, 2001.

HuERTA, Luis (2011): "Uniting Fiscal and Social Conservatism”, The New York Times, 5 de enero.

KymlickA, William (1995): Multicultural Citizenship, Oxford, Clarendon Press; trad. cast. de Carme Castells Auleda: Ciudadanía multicultural. Una teoría liberal de los derechos de las minorías, Barcelona, Paidós, 1996.

LAPORTA, Francisco (1987): "Sobre el concepto de derechos humanos", Doxa, núm. 4, pp. 23-46.

LÁZARO, Julio (2010): “El Abogado del Estado niega que los padres tengan el monopolio sobre la educación y las virtudes cívicas", El País, 28 de diciembre.

MACCORMICK, Neil (1990): Derecho legal y socialdemocracia. Ensayos sobre filosofía jurídica y política, Madrid, Tecnos. 
Macedo, Stephen (2000): Diversity and Distrust: Civic Education in a Multicultural Democracy, Cambridge, MA, Harvard University Press.

MANTECón SÁncho, Joaquín (2006): "El derecho de los padres a la educación de sus hijos según sus convicciones", ponencia presentada en la Jornada de Estudio sobre la Educación para la Ciudadanía organizada por la Conferencia Episcopal Española, 17 de noviembre de 2006.

Martí SÁnchez, José María (2007): “Objeciones de conciencia y escuela”, Revista General de Derecho canónico y Derecho Eclesiástico del Estado, núm. 15.

-(2010): "Homeschooling, ¿un derecho de los padres?”, ponencia presentada en el I Congreso Nacional de Educación en Familia, Valencia, 22-23 de octubre de 2010.

MCVICKER, Debra D. (1985): "The Interest of the Child in the Home Education Question: Wisconsin v. Yoder Re-examined", Indiana Law Review, núm. 18, pp. 711-729.

Nagel, Thomas (1991): Equality and Partiality, Oxford, Oxford University Press.

NAVArRo-VAlls, Rafael (2010): “La educación en casa o cuando el Estado invade la vida privada de sus ciudadanos", El Confidencial, 23 de diciembre.

OKIN, Susan M. (2002): "Mistresses of Their Own Destiny: Group Rights, Gender, and Realistic Rights of Exit", Ethics, núm. 112, pp. 205-30.

Raz, Joseph (1983): The Morality and Conflict, Cambridge, Mass., Harvard University Press.

RAWLS, John (1996): Liberalismo político, trad. cast. de Antoni Doménech, Barcelona, Crítica.

REDONDO, Ana María (2003): Defensa de la Constitución y enseñanza básica obligatoria (integración educativa intercultural y "homeschooling", Valencia, Tirant lo Blanch.

REICH, Robert (2002): "Testing the Boundaries of Parental Authority Over Education: The Case of Home schooling", en Stephen Macedo \& Yael Tamir (eds.), Political and Moral Education, NOMOS XLIII, Nueva York, New York University Press, pp. 275-313.

Reschly, Steven D. (2001): "Expanded Exercise: The Amish, Compulsory Education, and Religious Freedom", en John W. Johnson (ed.), Historic U.S. Court Cases: An Encyclopedia, Vol. II, Nueva York, Routledge, pp. 978-82.

RuANO EsPINA, Lourdes (2009): "El derecho a elegir en el ámbito escolar la educación religiosa y moral que esté de acuerdo con las propias convicciones en el marco de la LOLR", Revista General de Derecho Canónico y Derecho Eclesiástico del Estado, núm. 19, pp. 1-58.

Ruiz Miguel, Alfonso (1994): "Derechos liberales y derechos sociales", Doxa, 15-16, pp. 651-74. 
TAYLOR, Charles (1982): “The Diversity of Goods”, en Amartya Sen y Bernard Williams (eds.), Utilitarianism and Beyond, Cambridge, Cambridge University Press.

Tompkins, Dwight E. (1991): "An Argument for Privacy in Support of the Choice of Home Education by Parents", Journal of Law and Education, núm. 20, pp. 301-323.

WALDRON, Jeremy (1993): "Legislation and Moral Neutrality", en Liberal Rights. Collected Papers (1981-1991), Cambridge, Cambridge University Press, pp. 143-167.

WiLLIAMs, Bernard (1981): “Conflicts of Values", en Moral Luck, Cambridge, Cambridge University Press. 